\title{
Effect of intrathecal baclofen delivered by an implanted programmable pump on health related quality of life in patients with severe spasticity
}

Berrie Middel, Hanna Kuipers-Upmeijer, Jelte Bouma, Michiel Staal, Dettie Oenema, Theo Postma, Sijmon Terpstra, Roy Stewart

Northern Centre for Health Care Research, Faculty of Medical Sciences

B Middel

J Bouma

R Stewart

Department of Neurology

H Kuipers-Upmeijer

D Oenema

Department of Neurosurgery M Staal

Department of Long-Range Planning S Terpstra

Faculty of Economics, University of Groningen, the Netherlands

T Postma

Correspondence to: Berrie Middel, Northern Centre for Healthcare Research, University of Groningen, Ant Deusinglaan 1, 9713 AV Groningen, The Netherlands.

Received 1 October 1996 and in revised form

17 March 1997

Accepted 25 March 1997

\begin{abstract}
Objectives-To compare clinical effectiveness and health related quality of life in patients with severe spasticity who received intrathecal baclofen or a placebo. Methods-In a double blind, randomised, multicentre trial 22 patients were followed up during 13 weeks and subsequently included in a 52 week observational longitudinal study. Patients were those with chronic, disabling spasticity who did not respond to maximum doses of oral baclofen, dantrolene, and tizanidine. After implantation of a programmable pump patients were randomly assigned to placebo or baclofen infusion for 13 weeks. After 13 weeks all patients received baclofen. Clinical efficacy was assessed by the Ashworth scale, spasm score, and self reported pain, and health related quality of life by the sickness impact profile (SIP) and the Hopkins symptom checklist (HSCL).
\end{abstract}

Results-At three months the scores of the placebo and baclofen group differed slightly for the spasm score (effect size $=0.20$ ) and substantially for the Ashworth scale (effect size $=1.40$ ) and pain score (effect size $=0.94$ ); health related quality of life showed no significant differences. Three months after implantation the baclofen group showed a significant, substantial improvement on the SIP "physical health", "mental health", "mobility", and "sleep and rest" subscales and on the HSCL mental health scale; patients receiving placebo showed no change. After one year of baclofen treatment significant $(P<0.05)$ improvement was found on the SIP dimensions "mobility" and "body care and movement" with moderate effect sizes. Improvement on the SIP subscale "physical health" $(P<0.05$; effect size 0.86 ), the SIP overall score (without "ambulation"), and the "physical health" and overall scale of the HSCL was also significant, with effect sizes $>0.80$. Changes in health related behaviour were noted for "sleep and rest" and "recreation and pastimes" $(P<0.01, P<0.05$; effect size 0.95 and 0.63, respectively). Psychosocial behaviour showed no improvement.

Conclusions-Intrathecal baclofen delivered by an implanted, programmable pump resulted in improved self reported quality of life as assessed by the SIP, and HSCL physical health dimensions also suggest improvement.

(F Neurol Neurosurg Psychiatry 1997;63:204-209)

Keywords: baclofen; health related quality of life; clinical outcomes

Continuous intrathecal baclofen infusion via a subcutaneously implanted programmable pump has been used in the treatment of severe spasticity since 1984. Studies have evaluated neurological (Ashworth scale and spasm score), neurophysiological (EMG), urological (bladder function), and other clinically relevant outcomes, such as functional status activities of daily living. ${ }^{1-12}$ Little attention has been paid, however, to health related quality of life, health status measures, and costs. This study addresses health related dimensions of quality of life as well as conventional outcome measures, including muscle tone (Ashworth scale) and frequency of spasms. Treatment outcomes were evaluated during one year after pump implantation to assess the long term effects of baclofen treatment, which is aimed at relieving symptoms and improving function. Because of the multiple causes of severe spasticity, no disease specific instruments were available and health related quality of life was assessed by generic measures covering a wide range of health status domains.

To our knowledge, this is the first time validated health status measures have been used in a randomised, controlled, clinical trial to evaluate the results of baclofen treatment. This paper presents the results of a first wave of 22 patients who were enrolled in a double blind, placebo controlled, clinical trial and randomly assigned to a placebo condition or effective drug (baclofen) treatment. Data collection of a second wave of patients, who received baclofen infusion immediately after implantation of the programmable pump, is in progress.

\section{Methods}

SELECTION OF PATIENTS

Patients with severe spasticity caused by multiple sclerosis or spinal cord injury who had been referred by their general practitioner or specialist, were recruited from neurology, rehabilitation and neurosurgery departments of nine Dutch hospitals. Patients were included in the study when they met the following criteria: (1) 


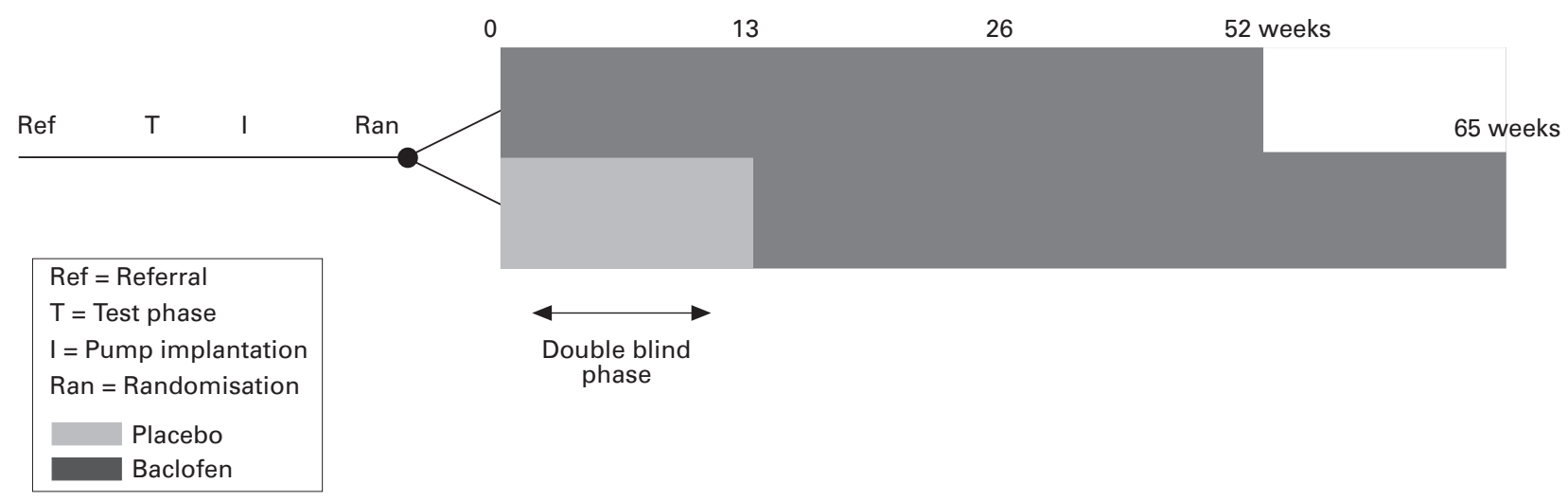

Study design.

aged 18 years or over, with chronic disabling spasticity of spinal origin inhibiting personal care, sitting, lying, and transfers, accompanied by pain and stiffness, or disturbed sleeping; (2) insufficient response to treatment with maximum doses of oral baclofen, dantrolene and tizanidine; (3) sufficient understanding of the consequences of the treatment. Patients were excluded when they were pregnant, had no neurological symptoms of supraspinal origin, or were allergic to baclofen.

After written consent was obtained, patients who fulfilled the inclusion criteria participated in a test phase to assess their responsiveness to baclofen. The maximum duration of the test phase was eight days. Every other day either baclofen or placebo was randomly administered by intrathecal bolus injections through a spinal catheter. Both doctor and patient were blinded during the test. Depending on the observed clinical effect consisting of improvement of at least 1 point on the Ashworth and spasm scales for eight hours, the test was repeated with an increased dose. All patients responded to one of the doses of baclofen (50, $75,100$, and $150 \mu \mathrm{g})$. At the start of the placebo controlled phase, patients were informed of the $50 \%$ chance of receiving a placebo for 13 weeks and of the possible risks and side effects of the treatment. Patients were aware that they could end their participation in the study and that this would not affect their care and treatment. All patients gave their consent in writing.

Using the Kolmogorov-Smirnov's test of normality ${ }^{13}$ we found that the normal distribution hypothesis had to be rejected for most of the variables used in the analysis. Therefore, we used the Wilcoxon matched pairs signed ranks test to estimate change scores between baseline and three months post-test. The difference in outcomes between the baclofen and placebo group at three months was analysed using the Wilcoxon-Mann-Whitney test for ordinal data. Effect sizes were calculated for the statistically significant results. According to Cohen, an effect size of 0.20 implies a small effect, 0.50 a medium effect, and $\geqslant 0.80$ a large effect. ${ }^{14}$

Due to lack of information on (clinical) indices from previous evaluations of patients with severe spasticity of spinal origin, we had no reliable figures to perform a power analysis and estimate the proper sample size.
STUDY DESIGN AND TREATMENT ASSIGNMENT A multicentre, randomised, double blind clinical trial was conducted to compare two groups of patients who were implanted with a programmable pump. During the first 13 weeks after implantation of a Synchro-Med programmable pump, the patients were randomly assigned to either baclofen $(n=12)$ or a placebo $(n=10)$. A balancing procedure was used to allocate the patients to the two conditions to achieve an equal distribution of patient characteristics with a potential effect on treatment outcomes over the two groups. ${ }^{15}$ The balancing criteria were age, sex, and aetiology of spasticity.

Both patient and doctor were blinded during the first 13 weeks after implantation. In patients assigned to the baclofen condition the pump was telemetrically started after implantation. The initial pump velocity was based on the patient's response during the test phase. If a patient's response had been satisfactory at 75 $\mu \mathrm{g}$ of baclofen, the initial day dosage was twice that dose $(150 \mu \mathrm{g}=6.25 \mu \mathrm{g} / \mathrm{h}(150 / 24=6.25)$. If response proved unsatisfactory, the velocity of the pump was increased by $10 \%$. A maximum of two increases was made during the placebo controlled phase. In patients assigned to the placebo condition, the same adjustment criteria were applied, but oral medication was maintained and at the end of the 13 week period the placebo was replaced by baclofen. Baclofen, placebo, and oral medication were supplied by the hospital pharmacist in a standard set of blank packages. The figure shows that the placebo controlled phase was followed by a 52 week observational longitudinal follow up phase which started as soon as the patient was put on continuous baclofen infusion. In patients receiving baclofen during the placebo controlled phase, the first phase coincided with the first 13 weeks of the second phase - that is, they were followed for a total of 52 weeks. In patients who were put on baclofen after 13 weeks of placebo, the two phases covered a period of $65(13+52)$ weeks.

The questionnaires were administered at the start of the study, at four and 13 weeks after the start of the placebo controlled phase, and at 26 and 52 weeks of the follow up phase.

The study received approval of the joint ethics committee of the Faculty of Medical 
Sciences, University of Groningen and University Hospital Groningen.

MEASURES

Ashworth scale and spasm score and self reported pain

The Ashworth scale and spasm score are clinical assessment scales for spasticity. To calculate the Ashworth score the grades for hip flexion/ extension, hip abduction and adduction, knee flexion/extension and ankle dorsal flexion/ extension on each side are summed and divided by eight. The modified Ashworth scale has 4 grades: grade 0 (no increase in tone), grade 1 (slight increase in tone, giving a "catch" when the affected part is moved in flexion or extension), grade 2 (more pronounced increase in tone, but affected part easily flexed), grade 3 (considerable increase in tone; passive movement difficult), and grade 4 (affected part rigid in flexion or extension). ${ }^{16}$ The spasm score evaluates the frequency of spasms with scores: 0 (no spasm), 1 (mild spasms induced by stimulation), 2 (infrequent spasms occurring less than once per hour), 3 (spasms occurring more than once per hour), and 4 (spasms occurring more than 10 times per hour).

Pain was measured on a 10 point self assessment scale with a sum score ranging from zero to 10 , where $0=$ having no pain and $10=$ having unbearable pain.

The sickness impact profile

The sickness impact profile (SIP) is a behaviour based self report measure that is used to quantify sickness related dysfunction. ${ }^{17} \mathrm{~Pa}-$ tients are asked to complete a standardised questionnaire consisting of 136 items aggregated into 12 domains of daily functioning. It has a physical dimension consisting of three domains by aggregation of the item scores of the ambulation, mobility, and body care and movement scales, and a psychosocial dimension including four scales - that is, social interaction, alertness behaviour, emotional behavior, and communication. The remaining, independent categories are not aggregated: sleep and rest, eating, work, home management, and recreation and pastimes. ${ }^{18}$ Differential weights per item are aggregated for each category and for both dimensions, and standardised to a percentage of the maximum possible score ranging from 0 to $100(0=$ no functional limitation for the category and $100=$ maximally possible limitation). As the patients in the study were unable to walk because of multiple sclerosis or spinal cord injury, the domains ambulation and home management were not considered. Only two patients had a part time paid job, so the category work was not included in the analysis.

\section{The Hopkins symptom check list}

The Hopkins symptom check list (HSCL) was translated and validated in the Dutch situation by Luteyn et al. ${ }^{19}$ It consists of 57 items with two subscales and an overall scale. The subscale physical health contains eight items with scores ranging from 0 to $24 \quad(0=$ no complaints at all) measuring the physical health experienced - for example, headache, low back pain, dizziness. The subscale mental health measures psychoneurotic complaints and consists of 17 items with scores ranging from zero to $51(0=$ no complaints at all). Some examples of items of this scale are: "I cannot get rid of nasty thoughts", "I am feeling desperate about the future". The overall scale covers all 57 items, including the 32 items of the subscales measuring psychoneurotic and somatic complaints, and ranges from zero to 171. According to Luteyn et al this scale is very sensitive to change in the evaluation of treatments.

\section{STATISTICAL METHODS}

The changes in clinical and health related quality of life at three months were analysed for the treatment and placebo group using the Wilcoxon matched pairs signed ranks test. The same test was used to analyse the results after one year of baclofen infusion. The differences at three months between the treatment and placebo group were analysed using the Wilcoxon-Mann-Whitney test for ordinal data. ${ }^{20}$ Effect sizes (d) were calculated according to Cohen. ${ }^{21}$ As the variance of the post-test measure is partly explained by the pretest scores, estimating the magnitude of the change between baseline and post-test in the treatment and control group required adjustment of the effect size d' for the correlation ( $r$ ) between the scores of paired observations.

$$
\begin{gathered}
\frac{\mathrm{d}=\mathrm{d}^{\prime}}{\sqrt{1-r}} \\
\mathrm{~d}^{\prime}=\text { effect size }=\frac{\overline{\mathrm{x}}_{\text {baseline }}-\overline{\mathrm{x}}_{\text {post-test }}}{\mathrm{SD}\left(\mathrm{X}_{\text {baseline }} \mathrm{X}_{\text {post-test }}\right)}
\end{gathered}
$$

$\mathrm{d}^{\prime}=$ effect size $=$ mean change $/$ pooled $\mathrm{SD}$ baseline and post-test score; $\mathrm{d}=$ effect size adjusted for $r ; r=$ correlation coefficient.

\section{Results}

Of 96 consecutive implantation candidates screened for inclusion in this study, 53 failed to meet the eligibility criteria because of suboptimal dosage of oral medication $(n=17)$, functional spasticity, or effective oral medication $(n=13)$, no spasticity $(n=3)$ or because they fulfilled one of the exclusion criteria $(n=20)$. Five of the 43 eligible subjects refused to participate. Of the remaining 38 patients, 22 were randomly assigned to placebo or baclofen using a balancing procedure. After the first wave of 22 patients had been assigned to the double blind controlled conditions, all 16 patients of the second wave received baclofen immediately after pump implantation. The results of the evaluation of clinical efficacy and health related quality of life in all 38 patients are not yet available, but will be published in due course.

DEMOGRAPHICS

Table 1 presents the overall characteristics. The mean (SD) age of the sample was 48.3 (12.7) 
Table 1 Patient characteristics of study groups and balancing criteria

\begin{tabular}{lll}
\hline & Baclofen & Placebo \\
\hline Age $^{\star}$ (mean) & 45.8 & 46.3 \\
Sex $^{\star}$ M & 5 & 5 \\
$\quad$ F & 7 & 5 \\
Aetiology & & \\
$\quad$ Multiple sclerosis & 7 & 6 \\
$\quad$ Spinal cord & 3 & 6 \\
Children (mean n) & 1.8 & 1.9 \\
\hline
\end{tabular}

^ Balancing criteria.

years (range 19-70), 55\% were women, and $59 \%$ and $41 \%$ had multiple sclerosis or spinal cord injury respectively. Seventeen patients (77\%) were married or divorced with an average number of two children. At the start of the study a relatively high proportion of patients with multiple sclerosis was enrolled. This was caused by a difference in consultancy function of the centres that first participated in the study and has led to a lower proportion of patients with spinal injury during the placebo controlled phase compared with the follow up phase.

DIFFERENCES BETWEEN THE GROUPS AFTER

THREE MONTHS

Our initial hypothesis was that the baclofen and placebo group would show differences in both clinical efficacy and physical and psychosocial functioning. To test the hypothesis we analysed the differences in mean scores on all the instruments during the first three months of the study (baseline to three months). At baseline, before implantation, no significant differences between the groups were found for the complete set of variables (Wilcoxon-MannWhitney test, $\alpha=0.05)$. For the three clinical efficacy measures, the null hypothesis - that is, equal mean scores at baseline and at three months post-test - could be rejected (table 2 , columns 8 and 9). The estimated magnitude of the difference in the spasm score was small (effect size $=0.20$ ); differences in the Ashworth scale (effect size $=1.40$ ) and pain score effect size $=0.94$ ) were large.

However, the physical and psychosocial dimensions of the health related quality of life measures showed no significant differences between the placebo and treatment group at baseline and after three months.

DIFFERENCES WITHIN THE BACLOFEN TREATMENT AND PLACEBO GROUP

Separate analysis of the two groups (table 2, column 6 and 7) showed no significant changes for any of the outcomes in the placebo group after three months. However, the baclofen group showed significant changes in the following outcome measures: spasm score $(P=0.04)$; Ashworth scale $(P=0.04)$, the overall SIP score $(P=0.03)$; the physical dimension of the SIP $(P=0.02)$; the SIP mobility scale $(P=0.005)$; the SIP scale sleep and rest $(\mathrm{P}=0.02)$; the SIP psychosocial behaviour scale $(P=0.04)$; the overall score of the HSCL $(P=0.002)$ and the mental health scale of the HSCL $(P=0.005)$. This trend is confirmed by the effect sizes which ranged from moderate to large (with values between 0.70 and 1.35 ) suggesting that baclofen infusion affected the domains of health related quality of life and clinical outcome in the predicted direction. Of the clinical efficacy data, the self reported pain score did not show a significant decrease during this period and the same applies for the HSCL physical health scale. Although the scores of the sickness impact profile dimensions eating, recreation and pastimes, body care and movement indicated an improvement after three months, the changes were not significant and are therefore not shown.

\section{RESULTS AFTER ONE YEAR OF BACLOFEN} ADMINISTRATION

Table 3 summarises the results of the evaluation of health outcome measures at baseline and one year after the start of intrathecal infusion of baclofen in the complete sample of patients with severe spasticity in the first wave of the study. Patients who were assigned to the 13 week placebo condition followed by baclofen treatment, were merged with the group who received baclofen from the start of the study. This observational longitudinal phase includes the entire initial sample of 22 patients, who were followed up during one year of intrathecal baclofen infusion. At one year patients showed substantial, significant improvement on clinical efficacy outcomes (self reported pain $\mathrm{P}<0.01$; effect size $=1.07$, Ashworth scale and spasm score $P<0.01$; effect size 6.23 and 3.05, respectively). Improvement was also found for the physical dimensions mobility and body care and movement of the SIP, indicating a statistically significant $(\mathrm{P}<0.05)$ change between baseline and posttest. The corresponding effect sizes suggest moderate changes in health related behaviour in these domains. Change was also significant and substantial for the physical health subscale of the SIP $(P<0.05$; effect size 0.86$)$. The SIP overall score (calculated without the ambulation items) and the physical health and overall scale of the HSCL showed a significant and substantial decrease (improvement) after 1 year, with large effect sizes $>0.80$. Changes in health related behaviour were observed for the categories sleep and rest and recreation and pastimes $(\mathrm{P}<0.01, \mathrm{P}<0.05$; effect size 0.95 and 0.63 respectively). In striking contrast to the physical dimensions, the psychosocial dimensions of the SIP (social interaction, alertness behaviour, emotional behaviour, and communication) and mental health of the HSCL did not show any significant improvement.

\section{Discussion}

As expected, the mean scores of the clinical efficacy scales (muscle tone, spasm score, and self reported pain) before and after treatment (table 3) showed a clear change in the predicted direction after one year of intrathecal baclofen infusion. ${ }^{22-24}$ These changes, which can be interpreted as an improvement in relevant clinical outcomes, are significant with large effect sizes. 
Table 2 Three month outcome of baclofen and placebo for severe spasticity $(n=22)$

\begin{tabular}{|c|c|c|c|c|c|c|c|c|}
\hline & \multirow{2}{*}{$\begin{array}{l}\text { Baseline score } \\
\text { Mean }(S D) \\
1\end{array}$} & \multirow{2}{*}{$\begin{array}{l}\text { After } 3 \text { months } \\
\text { Mean }(S D) \\
3 \quad 4\end{array}$} & \multirow[b]{2}{*}{$\underset{5}{\text { Effect sizet }}$} & \multicolumn{2}{|c|}{$\begin{array}{l}\text { Wilcoxon matched pairs signed } \\
\text { ranks }\end{array}$} & \multicolumn{2}{|c|}{$\begin{array}{l}\text { Mann-Whitney U Wilcoxon } \\
\text { rank sum }\end{array}$} & \multirow[b]{2}{*}{$\begin{array}{l}\text { Effect size } \\
10\end{array}$} \\
\hline & & & & $\begin{array}{l}z \text { Value } \\
6\end{array}$ & $\begin{array}{l}\text { Pvalue } \\
7\end{array}$ & $\begin{array}{l}z \text { Value } \\
8\end{array}$ & $\begin{array}{l}\text { Pvalue } \\
9\end{array}$ & \\
\hline \multicolumn{9}{|c|}{ Clinical efficacy: } \\
\hline \multicolumn{9}{|c|}{ Spasm score: } \\
\hline Baclofen & $2.23(0.54)$ & $1.65(1.11)$ & 0.74 & -1.78 & * & -2.32 & * & 0.20 \\
\hline Placebo & $1.83(0.66)$ & $1.81(0.76)$ & & -0.18 & NS & & & \\
\hline \multicolumn{9}{|c|}{ Ashworth scale: } \\
\hline Baclofen & $2.51(0.70)$ & $1.51(1.20)$ & 1.12 & -1.99 & 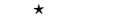 & -2.49 & $\star \star$ & 1.40 \\
\hline Placebo & $3.07(0.41)$ & $2.87(0.57)$ & & -1.25 & NS & & & \\
\hline \multicolumn{9}{|c|}{ Self reported pain score: } \\
\hline Baclofen & $4.20(2.98)$ & $2.75(3.22)$ & 0.72 & -1.35 & NS & -1.79 & $\star$ & 0.94 \\
\hline Placebo & $6.00(3.07)$ & $5.94(3.57)$ & & 0.00 & NS & & & \\
\hline \multicolumn{9}{|c|}{ SIPS: } \\
\hline \multicolumn{9}{|c|}{ Sleep and rest: } \\
\hline Baclofen & $12.33(12.27)$ & $16.20(10.35)$ & 0.71 & -1.99 & * & -1.21 & NS & \\
\hline Placebo & $21.71(16.84)$ & $21.38(11.09)$ & & -0.10 & NS & & & \\
\hline \multicolumn{9}{|l|}{ Mobility: } \\
\hline Baclofen & $31.99(17.40)$ & $16.69(12.29)$ & 1.35 & -2.50 & $\star \star$ & -2.32 & NS & \\
\hline Placebo & $38.84(24.09)$ & $35.88(24.60)$ & & -0.42 & NS & & & \\
\hline \multicolumn{9}{|c|}{ Physical dimension: } \\
\hline Baclofen & $39.98(9.78)$ & $35.10(5.41)$ & 1.07 & -1.99 & 夫 & -1.31 & NS & \\
\hline Placebo & $42.80(12.73)$ & $39.53(11.49)$ & & -1.54 & NS & & & \\
\hline \multicolumn{9}{|c|}{ Psychosocial dimension: } \\
\hline Baclofen & $16.03(13.69)$ & $12.26(9.87)$ & 0.74 & -1.68 & * & -0.73 & NS & \\
\hline Placebo & $42.80(12.73)$ & $39.53(11.49)$ & & -0.06 & NS & & & \\
\hline \multicolumn{9}{|c|}{ SIP overall score: } \\
\hline Baclofen & $31.72(9.80)$ & $27.79(5.32)$ & 1.00 & -1.78 & * & -0.82 & NS & \\
\hline Placebo & $30.12(10.64)$ & $28.98(8.83)$ & & -0.18 & NS & & & \\
\hline \multicolumn{9}{|c|}{ HSCL $\uparrow:$} \\
\hline \multicolumn{9}{|c|}{ Physical health: } \\
\hline Baclofen & $4.17(3.16)$ & $4.00(3.44)$ & & -1.01 & NS & -0.076 & NS & \\
\hline Placebo & $5.78(4.05)$ & $4.44(3.00)$ & & -0.82 & NS & & & \\
\hline \multicolumn{9}{|c|}{ Mental health: } \\
\hline Baclofen & $7.83(4.97)$ & $5.00(4.28)$ & 1.28 & -2.50 & $\star \star$ & -0.086 & NS & \\
\hline Placebo & $6.89(7.20)$ & $7.33(6.69)$ & & -0.10 & NS & & & \\
\hline \multicolumn{9}{|c|}{ HSCL overall score: } \\
\hline Baclofen & $30.0 \quad(12.54)$ & $20.67(11.78)$ & 1.34 & -2.79 & $\star \star \star$ & -0.099 & NS & \\
\hline Placebo & $31.0 \quad(21.62)$ & $28.22(18.43)$ & & -0.82 & NS & & & \\
\hline
\end{tabular}

Table 3 Clinical outcome measures, health related functional status, perceived physical and mental health and depression at baseline, one year after baclofen infusion and changes in (sub) scale scores, and effect sizes

\begin{tabular}{|c|c|c|c|c|c|}
\hline Instrument subscale & $\begin{array}{l}\text { Baseline score } \\
\text { mean (SD) }\end{array}$ & $\begin{array}{l}1 \text { year after baclofen score } \\
\text { mean (SD) }\end{array}$ & z Value & Pvalue & Effect size \\
\hline Ashworth scale & $2.87(0.54)$ & $0.44(0.51)$ & -3.52 & 0.002 & 6.23 \\
\hline Self reported pain score & $4.57(3.23)$ & $1.97(2.95)$ & -2.35 & 0.009 & 1.07 \\
\hline Spasm score & $2.16(0.48)$ & $0.62(0.75)$ & -3.42 & 0.003 & 3.05 \\
\hline \multicolumn{6}{|l|}{ Sickness impact profile categories: } \\
\hline Sleep and rest & $20.48(12.48)$ & $13.99(10.53)$ & -2.20 & 0.01 & 0.95 \\
\hline Recreation and pastimes & $42.47(22.47)$ & $30.53(22.35)$ & -1.70 & 0.04 & 0.63 \\
\hline \multicolumn{6}{|l|}{ Ambulation ${ }^{\star}$} \\
\hline Mobility & $35.10(19.64)$ & $25.16(19.50)$ & -2.07 & 0.02 & 0.73 \\
\hline Body care and movement & $50.62(19.30)$ & $41.44(18.72)$ & -1.94 & 0.02 & 0.64 \\
\hline SIP physical dimension & $41.48(8.07)$ & $33.44(12.73)$ & -1.85 & 0.03 & 0.86 \\
\hline SIP psychosocial dimension & $14.80(11.72)$ & $10.96(10.18)$ & -1.54 & NS & - \\
\hline SIP overall score & $31.28(7.93)$ & $25.13(9.61)$ & -2.48 & 0.005 & 0.99 \\
\hline \multicolumn{6}{|l|}{ Hopkins symptoms check list: } \\
\hline Physical health & $4.89(2.87)$ & $3.66(3.03)$ & -2.19 & 0.01 & 0.86 \\
\hline Mental health & $7.17(5.26)$ & $5.44(4.57)$ & -1.29 & NS & \\
\hline HSCL total score & $29.00(12.71)$ & $22.11(12.09)$ & -2.22 & 0.01 & 0.87 \\
\hline
\end{tabular}

* The items of the SIP ambulation scale were not applicable for the patients in this study and were removed.

We can conclude that intrathecal baclofen delivered by a subcutaneously implanted programmable pump resulted in a significant improvement in self reported health related quality of life regarding recreation and pastimes, rest and sleep, mobility, body care and movement as assessed with the sickness impact profile. The changes between the initial and final scores on the physical health dimension and the overall scores of the sickness impact profile and the Hopkins symptom checklist also point to improvement. No change was found for the SIP and HSCL psychosocial dimensions. Significant improvements are associated with effect sizes $>0.63$. For non-significant changes the effect sizes ranged from 0.40 to 0.57 .

Contrary to our expectations, three months after implantation the baclofen group and the placebo group did not differ significantly in the mean scores on the physical and psychosocial dimensions of health related quality of life instruments.

It was hypothesised that no significant changes would be found in the placebo group but a significant change was expected to have occurred in the baclofen group at three months. The group receiving baclofen immedi- 
ately after implantation improved significantly on the clinical outcome measures, demonstrating the clinical efficacy of the treatment. This group showed significant changes in relevant physical and psychosocial dimensions of self reported health status except for the HSCL physical health scale.

\section{Conclusion}

In interpreting the results of this study, one should bear in mind that the research design may have caused some underestimation of the results. The following considerations are important in this respect:

(1) In the placebo phase of the study the pump could not be optimally programmed because the doctor who was responsible for the treatment was blinded. In patients assigned to the placebo condition this would have led to countless increases in the concentration of the contents or the velocity of the pump. Therefore, we decided to restrict the number of changes in velocity and/or concentration to two. This may have resulted in suboptimal doses for some of the patients in the baclofen group, which in turn may have affected treatment outcome. Thus the observed differences between the baclofen and placebo group may not be representative of optimal treatment results.

(2) Three months is probably too short a period to find evidence of differences in dimensions of health related quality of life between the treatment and baclofen group. Despite the significant and substantial observed change in clinical efficacy in the baclofen group, these patients continue to have other invalidating consequences of their underlying disease. This might explain the lack of significant differences in health related quality of life between patients receiving baclofen and placebo.

(3) The necessity of blinding, even if the outcome seems too obvious, was shown by changes in spasticity and health related behaviour in one of the patients in the placebo group. For several weeks both patient and research team erroneously assumed that these changes were attributable to baclofen.

(4) In cases where the optimum dosage was achieved after two corrections there is the probability of habituation causing a reduction in the effects after the first four weeks.

(5) Aspects of physical health and daily functioning are probably associated with the degree of spasticity. Therefore, a reduction in severe spasticity is likely to induce a substantial change in the dimensions of physical health. The psychosocial dimensions, however, are probably more strongly associated with the unchangeable, underlying disease, which may explain the absence of a treatment effect in this respect even after one year.
(6) The improvement on the psychosocial dimensions of quality of life during the first three months is probably associated with patients receiving increased attention from medical professionals and their social network combined with (too) high expectations of the treatment. This effect is likely to disappear after one year of treatment.

This study was supported through a grant from the Dutch Sickfund Council. Appreciation is expressed to Ms Mereke Gorsira for assistance in preparing the manuscript.

1 Müller H, Zierski J, Dralle D, et al. Intrathecal baclofen in spasticity. In: Müller H, Zierski J, Penn RD, eds. Local spinal therapy of spasticity. Berlin-Heidelberg: Springer Verlag, 1988.

2 Nance P, Schryvers O, Schmidt B, et al. Intrathecal baclofen therapy for adults with spinal spasticity: therapeutic 1995;22:22-9.

3 Albright L, Barron A, Fasick MP, et al. Continuous intrathecal baclofen infusion for spasticity of cerebral origin. fAMA 1993;270:247-57.

4 Coffey RJ, Cahill D, Steers W, et al. Intrathecal baclofen for intractable spasticity of spinal origin: results of a long-term multicenter study. I Neurosurg 1993;78:226-32.

5 Meythaler JM, Steers WD, Tuel SM, et al. Continuous intrathecal baclofen in spinal spasticity: a prospective study. Am F Phys Med Rehabil 1992;6:321-27.

6 Steinbok P, Daneshvar H, Evans D, Kestle JRW. Cost analysis of continuous intrathecal baclofen versus selective functional posterior rhizotomy in the treatment of spastic quadriplegia associated with cerebral palsy. Pediatr Neurosurg 1995;22:255-65.

7 Saltuari L, Kronenberg M, Marosi MJ, et al. Indication, efficiency and complications of intrathecal pump supported ciency and complications of intrathecal pump supported
baclofen treatment in spinal spasticity. Acta Neurol Napoli baclofen treatm

8 Ochs G, Delhaas EM. Long-term experience with intrathecal use of baclofen in severe spasticity. In: Lakke JPWF, Delhaas EM, Rutgers AWF, eds. Parental drug therapy in spasticity and Parkinson's disease. Carnforth: The Parthenon Publishing Group Limited, 1992.

9 Loubser PG, Narayan ChRK, Sandin KJ, et al. Continuous infusion of intrathecal baclofen: long-term effects on spasticity in spinal cord injury. Paraplegia 1991;29:48-64.

10 Teddy P, Jamous A, Gardner B, et al. Complications of intrathecal baclofen delivery. Brf F Neurosurg 1992;6:115-8.

11 Penn RD. Intrathecal baclofen for spasticity of spinal origin: seven years of experience. F Neurosurg 1992;77:236-40.

12 Patterson V, Watt M, Byrnes D, et al. Management of severe spasticity with intrathecal baclofen delivered by a manually operated pump. $\mathcal{f}$ Neurol Neurosurg Psychiatry 1994;57: operated

13 Bennett C, Franklin NL. Statistical analysis in chemistry and the chemical industry. New York: John Wiley, 1961

14 Cohen J. A power primer. Psychol Bull 1992;1:155-9.

15 Zielhuis GA, Straatman H, Van 't Hof-Grootenboer AE, et al. The choice of a balanced allocation method for a clinical trial in otitis media with effusion. Stat Med 1990;9:23746.

16 Ashworth B. Preliminary trial of carisoprodal in multiple sclerosis. Practitioner 1964;192:540-2.

17 Bergner M, Bobbitt RA, Carter WB, Gilson BS. The sickness impact profile: development and final revision of a health status measure. Med Care 1981;19:787-805.

18 De Bruin AF. The measurement of sickness impact: the De Bruin AF. The measurement of sickness impact: the
construction of the SIP-68 [dissertation]. Maastricht: Univerconstruction of the SIP-68 [dissertation]. Maastricht
sity of Limburg, 1994 (ISBN90-74421-02-4)

19 Luteyn F, Hamel LF, Bouman TK, et al. Hopkins symptom checklist (manual). Lisse: Swets and Zeitlinger, 1984.
chen

20 Siegel S, Castellan N.J. Non-parametric statistics for the behavioural sciences. New York: McGraw-Hill, 1988.

21 Cohen J. Statistical power analyses for the behavioural sciences. New York: Academic Press, 1977.

22 McLean BN. Intrathecal baclofen in severe spasticity. $\mathrm{Br} \mathcal{F}$ Hosp Med 1993;49:262-67.

23 Hugenholtz H, Nelson RF, Dehoux E, Bickerton R. Intrathecal baclofen for intractable spinal spasticity-a double blind cross-over comparison with placebo in 6 patients. Can 7 Neurol Sci 1992;19:188-95.

24 Azouvi P, Mane M, Thiebaut JB, Denys P, Remy-Neris O, Bussel B. Intrathecal baclofen administration for control of severe spinal spasticity: functional Improvement and longterm follow up. Arch Phys Med Rehabil 1996;77:35-9. 